\title{
Experimental Safety Evaluation of Original Article Inflated Assisting Balloons for Endovascular Surgery
}

Masataka Takeuchi, ${ }_{1,2}$ Atsushi Uyama, ${ }^{1}$ Takashi Matsumoto, ${ }^{1}$ Kazuma Tsuto, ${ }^{1}$ Yoshifumi Konishi, ${ }_{1}^{1}$ and Satoshi Iwabuchi ${ }^{3}$

Objective: The balloon-assisted technique is one of the methods used for cerebral aneurysm embolization. There are several applications of assisting balloons such as remodeling the neck of cerebral aneurysms, protecting blood vessel branches, and stabilizing the microcatheter. In this study, we measured the pressure inside inflated assisting balloons to assess safety or procedure.

Methods: A T-junction silicone model was used. The pressure inside the balloon inflated to the set herniation levels in the T-junction model was measured using a fiber pressure sensor. We compared the pressure and difference between each assisting balloon.

Results: The pressure required for inflating the balloon to the set herniation level in the T-junction model varied depending on the type of assisting balloon. The results suggest that differences in pressure among inflated balloons are likely attributable to differences in the materials used in the lumens of the balloons.

Conclusion: The pressure inside various inflated assisting balloons was measured for comparison and differences were found. This experiment contributes to the safety of the balloon-assisted technique.

Keywords $>$ assist balloon, endovascular surgery, experimental safety evaluation, cerebral aneurysm

\section{Introduction}

Coil embolization was traditionally contraindicated for irregularly shaped, wide-necked, and/or large cerebral aneurysms, ${ }^{1,2)}$ but its indications have expanded due to some adjunctive techniques (i.e., balloon-assisted technique) and vascular reconstruction device (VRD). ${ }^{3-5)}$ In addition, pipeline embolization device (PED) as fluid flow dynamics was developed. ${ }^{6-8)}$ Assisting balloons are widely

${ }^{1}$ Department of Neurosurgery, Seishou Hospital, Odawara, Kanagawa, Japan

${ }^{2}$ Department of Neurosurgery, Toho University Graduate School of Medicine, Tokyo, Japan

${ }^{3}$ Department of Neurosurgery (Ohashi), School of Medicine, Faculty of Medicine, Toho University, Tokyo, Japan

Received: December 1, 2020; Accepted: February 1, 2021 Corresponding author: Masataka Takeuchi. Department of Neurosurgery, Seishou Hospital, 1-16-35, Ougicho, Odawara, Kanagawa 250-0001, Japan

Email: masatakatakeuchi@hotmail.com

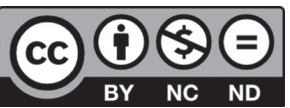

This work is licensed under a Creative Commons Attribution-NonCommercialNoDerivatives International License.

(C)2021 The Japanese Society for Neuroendovascular Therapy used for treatment of wide-necked or bifurcation cerebral aneurysms: they are an essential device in endovascular treatment of such cerebral aneurysms and have various applications such as remodeling the neck of cerebral aneurysms, protecting side branches, immobilizing the microcatheter, and controlling blood flow. In this study, several types of assisting balloons were inflated using a T-junction silicone model, and pressures inside balloons inflated to the herniation level were measured for comparison.

\section{Materials and Methods}

Several types of assisting balloons were inflated using a T-junction silicone blood vessel model, and pressures inside the balloon inflated to the set herniation levels in the side branch of the T-junction were measured using a fiber pressure sensor (Fig. 1). More precisely, a balloon was inflated by injecting saline using a precision syringe (OSAKA CHEMICAL, Osaka, Japan). The pressure inside the balloon was measured using a fiber pressure sensor (MA2899-014; FISO Technologies, Quebec, Canada; Fig. 2). ${ }^{9}$ An aqueous ink was added to the saline to increase the visibility of changes in balloon shape upon 


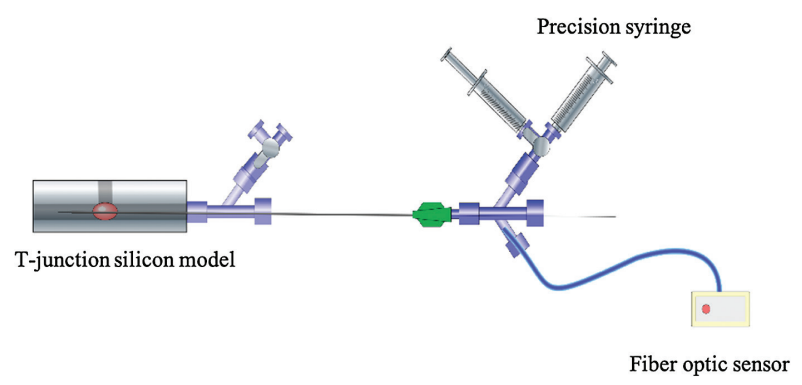

Fig. 1 Assisting balloon evaluation system.

inflation. The diameter of the silicone blood vessel model was $3 \mathrm{~mm}$ (Fig. 3), and the experiments were performed at room temperature and humidity. Selected assist balloon list for coil embolization is shown in Table 1. Four measurements were taken per condition. We compared the pressure and difference between each assisting balloon.

\section{Results}

The pressures required for inflating each type of balloon to the herniation level in the side branch of the T-junction model are shown in Fig. 4. The pressure required for inflating the balloon to the herniation level of $3.5 \mathrm{~mm}$ was the lowest for the SHOURYU HR balloon $(4 \mathrm{~mm} \times 7 \mathrm{~mm}$; Kaneka, Osaka, Japan), followed by the SHOURYU HR balloon $(7 \mathrm{~mm} \times 7 \mathrm{~mm})$, the Scepter XC balloon $(4 \mathrm{~mm} \times$ $11 \mathrm{~mm}$; Microvention, Tustin, CA, USA), HyperForm balloons $(4 \mathrm{~mm} \times 7 \mathrm{~mm}$ and $7 \mathrm{~mm} \times 7 \mathrm{~mm}$; Covidien/ev3 Endovascular, Irvine, CA, USA), and the TransForm SC balloon (4 mm $\times 7 \mathrm{~mm}$; Stryker Kalamazoo, MI, USA). The pressure required for inflation to the herniation level of $4.5 \mathrm{~mm}$ was the lowest for the SHOURYU HR balloon $(7 \mathrm{~mm} \times 7 \mathrm{~mm}$ ), followed by the SHOURYU HR balloon $(4 \mathrm{~mm} \times 7 \mathrm{~mm})$ and the Scepter XC balloon $(4 \mathrm{~mm} \times$ $11 \mathrm{~mm}$; MicroVention, Tustin, CA, USA): the pressure was higher than $700 \mathrm{mmHg}$ and thus was not measurable for the HyperForm balloons $(4 \mathrm{~mm} \times 7 \mathrm{~mm}, 7 \mathrm{~mm} \times 7 \mathrm{~mm})$ and the TransForm SC balloon $(4 \mathrm{~mm} \times 7 \mathrm{~mm})$. Measurement errors were within $5 \mathrm{mmHg}$ for all assisting balloons. No defects in the balloons were observed after the experiment.

Figure $\mathbf{5}$ shows the images of balloons inflated to the herniation level of $4.5 \mathrm{~mm}$ in the T-junction silicone model. Each assisting balloon had radiopaque markers at both ends. When overinflated, the balloon lumen expanded beyond the radiopaque markers and the balloon shaft shifted: such morphologies varied among the different types of balloons.

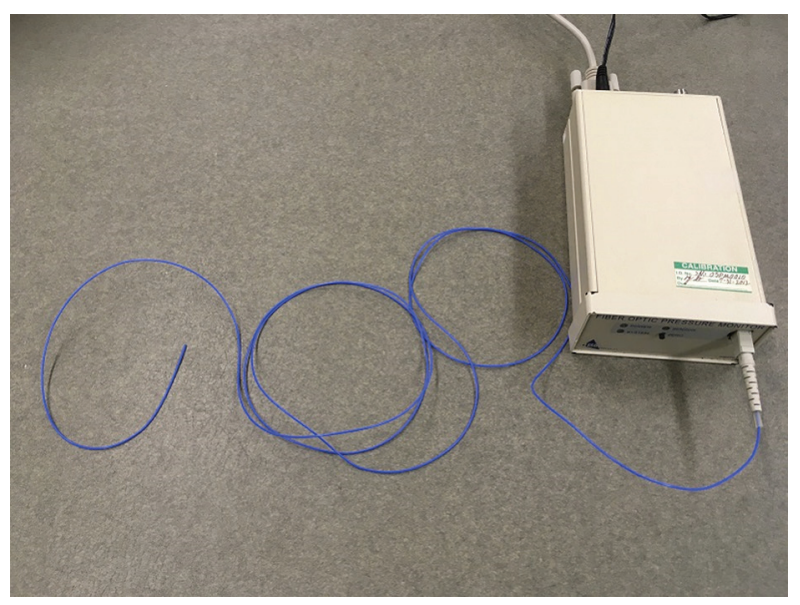

Fig. 2 Fiber pressure sensor.

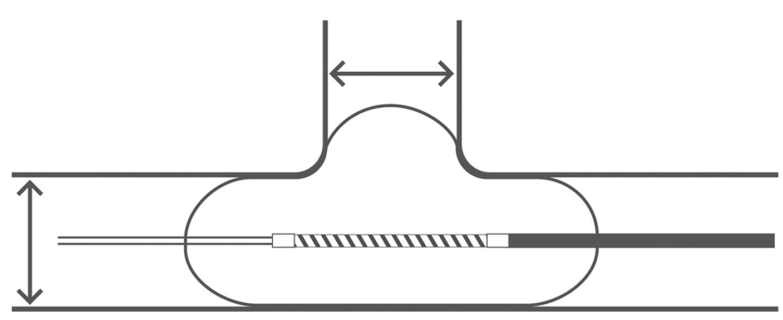

Fig. 3 T-junction silicone vessel model. The lumen of each vessel is $3 \mathrm{~mm}$.

\section{Discussion}

Our experiments revealed differences in the inner pressure among inflated assisting balloons. The shape of the inflated assist balloon can be confirmed. However, the pressure on the vessel wall due to the inflated assist balloon is unknown. There is no report comparing the inner pressure of the balloons during each assist balloon inflation. Therefore, this experiment is highly useful for the purpose of safe use of assisting balloons.

The SHOURYU HR balloon $(4 \mathrm{~mm} \times 7 \mathrm{~mm})$ showed the lowest inner pressure when inflated to the herniation level of $3.5 \mathrm{~mm}$, whereas the SHOURYU HR balloon $(7 \mathrm{~mm} \times 7 \mathrm{~mm})$ showed the lowest inner pressure when inflated to the herniation level of $4.0 \mathrm{~mm}$ and $4.5 \mathrm{~mm}$. It is likely that the SHOURYU HR balloons are flexible and that they inflated to fit the vessel shape. Also, when overinflated to the maximum herniation level tested $(4.5 \mathrm{~mm})$, the inner pressure was lower for the SHOURYU HR balloon $(7 \mathrm{~mm} \times 7 \mathrm{~mm})$ than for the SHOURYU HR balloon $(4 \mathrm{~mm} \times 7 \mathrm{~mm})$. When cerebral aneurysms are irregularly shaped, bifurcated, and/or wide-necked, inadequate coil packing is reported to occur, and consequent re-increases in aneurysm size and rupture resulted in repeat surgery. ${ }^{10,11)}$ 
Table 1 Various assist balloons used in the experiment

\begin{tabular}{|c|c|c|c|c|}
\hline & SHOURYO HR & HyperForm & Scepter XC & TransForm SC \\
\hline Developer & Kaneka, Osaka, Japan & $\begin{array}{l}\text { Covidien/ ev3 Endovascular, } \\
\text { Irvine, CA, USA }\end{array}$ & $\begin{array}{l}\text { MicroVention, Tustin, } \\
\text { CA, USA }\end{array}$ & $\begin{array}{l}\text { Stryker, Kalamazoo, } \\
\text { MI, USA }\end{array}$ \\
\hline Wire lumen & Single lumen & Single lumen & Double lumen & Single lumen \\
\hline Balloon material & Syrene-based elastomer & Chloroprene & Special polyurethane & Chloroprene \\
\hline Test sample & $\begin{aligned} \text { SHOURYO HR } 4 \times 7 \\
7 \times 7\end{aligned}$ & $\begin{array}{r}\text { HyperForm } 4 \times 7 \\
7 \times 7\end{array}$ & Scepter XC $4 \times 11$ & TransForm SC $4 \times 7$ \\
\hline Effective length & $150 \mathrm{~cm}$ & $150 \mathrm{~cm}$ & $150 \mathrm{~cm}$ & $150 \mathrm{~cm}$ \\
\hline Combined GW & TENROU 0.014 & X-pedion10 0.010 & Traxcess 0.014 & Transend Soft Tip 0.014 \\
\hline
\end{tabular}

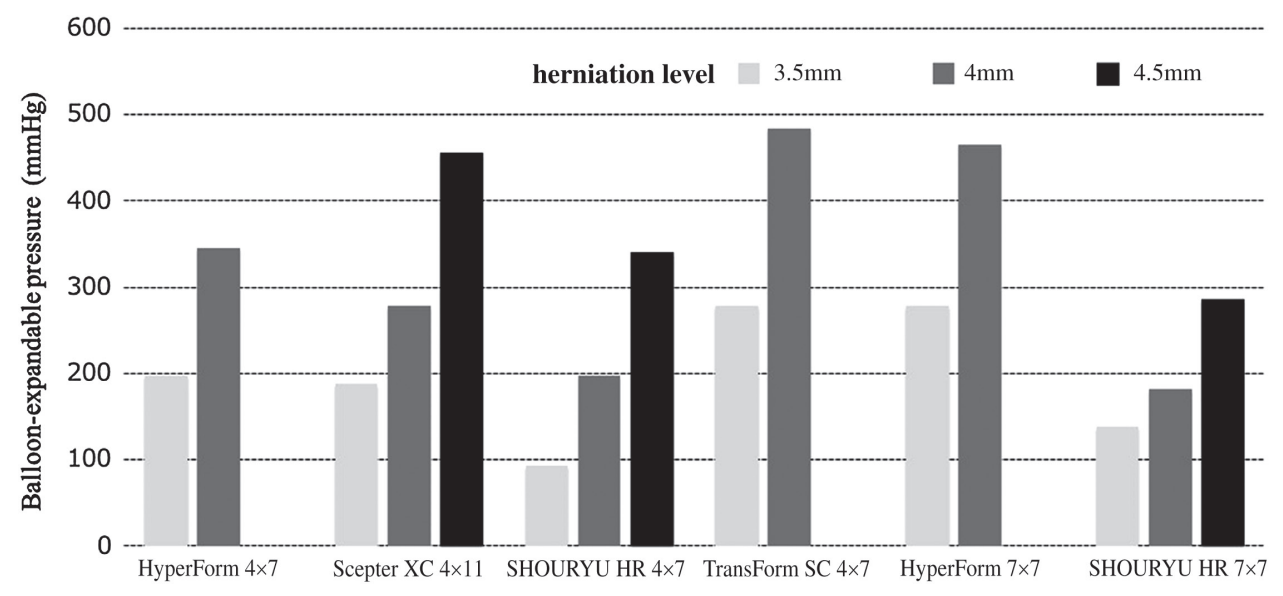

Fig. 4 Pressure inside various balloon at the herniation height.

Such cerebral aneurysms are treated by the remodeling technique (also called the herniation technique) in which an assisting balloon is overinflated to create the neck of aneurysms and to protect side branches. This study showed that the inflated balloons fit the shape of the blood vessel model. It is ideal for the balloon to inflate along the blood vessel, generating low pressure against the parent vessel wall. Our results showed that the SHOURYU HR balloon performed best in this experiment, with the size of $7 \mathrm{~mm} \times$ $7 \mathrm{~mm}$, rather than $4 \mathrm{~mm} \times 7 \mathrm{~mm}$, preferable for this application. SHOURYU HR balloons should be selected if there is a risk of vessel damage due to overinflated of the wide neck aneurysm or atherosclerotic vessels. Balloons that protect the neck of the aneurysm and side branches, and that moderately pressurize the parent vessel, provide low pressure for microcatheter immobilization and packed coil protection.

Thromboembolic complications and vessel dissection have been reported in patients following balloon-assisted coil embolization, ${ }^{12)}$ presumably because of the formation of thrombi due to temporary reduction in blood flow and damage to vascular endothelial cells upon balloon inflation. There are three types of balloon inflation-associated mechanical stress acting on the blood vessel wall, namely, shearing stress, stretching, and pressure load, ${ }^{13-16)}$ but damages to the blood vessels caused by such mechanical stress have not yet been studied in detail. The reason is that, upon inflation of the balloon, abrasion-induced shearing stress acting on vascular endothelial cells, pressure load perpendicular to the vessel walls, and vessel stretching in the circumferential direction and the long-axis direction, all occur abruptly at the same time. In vitro studies of balloon injuries during percutaneous angioplasty showed that endothelial cell death and damage to smooth muscle cells increased with increasing balloon inflation pressure and duration. ${ }^{17,18)}$ A considerable effect on the arrangement of smooth muscle cells, a characteristic of balloon overinflation, is a likely cause of blood vessel dissociation. ${ }^{19,20)}$ Information about the balloon diameter when inflated with a certain injection volume, the recommended injection volume, and the maximum injection volume is provided for each balloon, but the information about the inner pressure of the balloon in relation to the diameter upon inflation is not available. The experiment performed in this study provides quantitative data on the pressure inside balloons, enabling the relative evaluation of mechanical stress acting on the vessel walls. Thus, these results will be useful for safety assessment. 

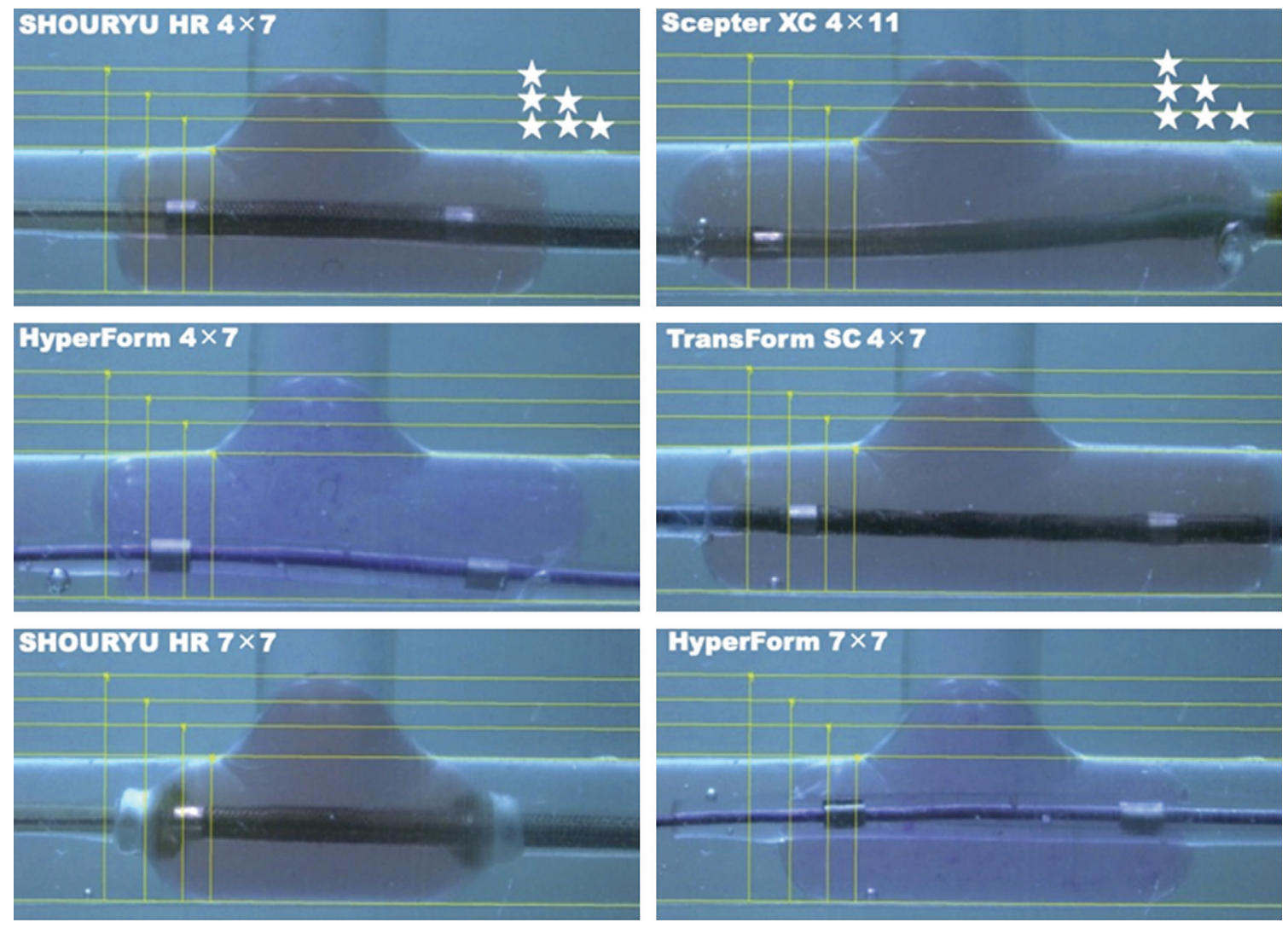

Fig. 5 In the T-junction silicone vessel model, each assisting balloon shows a change in shape when overinflated to $4.5 \mathrm{~mm}$. * Top line: $4.5 \mathrm{~mm}$; ${ }^{* *}$ Middle line: $4.0 \mathrm{~mm}$; ${ }^{* *}$ Bottom line: $3.5 \mathrm{~mm}$.

The materials used in the balloon lumen are likely to be the predominant cause of the differences in pressure inside inflated balloons. SHOURYU HR balloons are made of styrene-based elastomers. Elastomer is a word created by combining elastic and polymer. Styrene-based elastomers are used for the soft segment to provide elasticity and flexibility while the hard segment plays a role in shape stability at room temperature although it becomes fluid at high temperature. The balance between these two resin materials determines stretchability and elasticity. The results of this study suggest that styrene-based elastomers, the material of SHOURYU HR balloons, are very stretchable. On the other hand, the inner pressures of overinflated HyperForm and TransForm SC balloons were slightly high suggesting that their lumen material (chloroprene) was very elastic. These balloons are recommended to be inflated with straight blood vessels. And it should be avoided when the difference in blood vessel diameter is large. It has been reported that a balloon is useful for rescue of an inadequately expanded PED by achieving wall apposition of the stent through expansion of its inner lumen. ${ }^{21)}$ Highly elastic HyperForm or TransForm SC balloons will be suitable for this application.
There are single-lumen balloons (SHOURYU HR, HyperForm, and TransForm SC balloons) and doublelumen balloons (Scepter XC balloons). A single-lumen balloon is made more expandable by sealing the end of the catheter with a wire, but they are difficult to navigate to target vessel. Meanwhile, double-lumen balloons are easier to navigate to target vessel but take a long time to inflate and deflate, and operators sometimes feel resistance while inflating them. Because of this, double-lumen balloons are expected to be elastic and produce high pressure when inflated. However, the pressure inside the Scepter XC balloon was the second lowest, following that inside SHOURYU HR balloons, when inflated to the herniation level of $4.5 \mathrm{~mm}$. Our results indicate that assisting balloons should be chosen according to their application in endovascular treatment based on blood vessel anatomy.

With the introduction of VRD and PED, endovascular treatment is becoming the main treatment option for cerebral aneurysms, but VRD and PED are associated with risk of thromboembolic complications. Perioperative antiplatelet therapy is therefore essential, ${ }^{22)}$ and as a result, VRD and PED are contraindicated when adjunctive antiplatelet therapy is not possible. Assisting balloons will remain an 
essential device in endovascular treatment for such cases in the future.

\section{Conclusion}

Pressure inside inflated assisting balloons was measured. The pressure differed among different types of assisting balloons, and the quantitative data obtained were indicative of safety. The findings of this study contribute to selecting suitable assisting balloons according to the application, as well as to the safety of endovascular therapy.

\section{Disclosure Statement}

All authors have no conflict of interest to declare.

\section{References}

1) Molyneux AJ, Kerr RS, Yu LM, et al: International subarachnoid aneurysm trial (ISAT) of neurosurgical clipping versus endovascular coiling in 2143 patients with ruptured intracranial aneurysms: a randomised comparison of effects on survival, dependency, seizures, rebleeding, subgroups, and aneurysm occlusion. Lancet 2005; 366: 809-817.

2) Zorman MJ, lorga $R$, Ma R, et al: Management of aneurysmal subarachnoid haemorrhage 17 years after the ISAT trial: a survey of current practice in the UK and Ireland. $\mathrm{Br}$ J Neurosurg 2019; 17: 1-4.

3) Moret J, Cognard C, Weill A, et al: The "remodelling technique" in the treatment of wide neck intracranial aneurysms. Angiographic results and clinical follow-up in 56 cases. Interv Neuroradiol 1997; 30: 21-35.

4) Levy DI, Ku A: Balloon-assisted coil placement in widenecked aneurysms. Technical note. J Neurosurg 1997; 86: 724-727.

5) Wajnberg E, de Souza JM, Marchiori E, et al: Singlecenter experience with the Neuroform stent for endovascular treatment of wide-necked intracranial aneurysms. Surg Neurol 2009; 72: 612-619.

6) Miyachi S, Hiramatsu R, Ohnishi H, et al: Usefulness of the pipeline embolic device for large and giant carotid cavernous aneurysms. Neurointervention 2017; 12: 83-90.

7) Becske T, Potts MB, Shapiro M, et al: Pipeline for uncoilable or failed aneurysms: 3-year follow-up results. J Neurosurg 2017; 127: 81-88.

8) Yeung TW, Lai V, Lau HY, et al: Long-term outcome of endovascular reconstruction with the pipeline embolization device in the management of unruptured dissecting aneurysms of the intracranial vertebral artery. J Neurosurg 2017; 116: 882-887.
9) Cibula E, Pevec S, Lenardic B, et al: Miniature all-glass robust pressure sensor. Opt Express 2009; 17: 5098-5106.

10) Morales HG, Kim M, Vivas EE, et al: How do coil configuration and packing density influence intra-aneurysmal hemodynamics? AJNR Am J Neuroradiol 2011; 32: 1935-1941.

11) Pichamuthy J, Feroze R, Chung T, et al: Cerebral aneurysm wall stress after coiling depends on morphology and coil packing density. J Biomech Eng 2019; 10: 1115.

12) Cekirge HS, Yavuz K, Geyik S, et al: HyperForm balloon remodeling in the endovascular treatment of anterior cerebral, middle cerebral, and anterior communicating artery aneurysms: clinical and angiographic follow-up results in 800 consecutive patients. J Neurosurg 2011; 114: 944-953.

13) Di Francesco L, Totani L, Dovizio M, et al: Induction of prostacyclin by steady laminar shear stress suppresses tumor necrosis factor-alpha biosynthesis via heme oxygenase-1 in human endothelial cells. Circ Res 2009; 104: 506-513.

14) Richard MN, Deniset JF, Kneesh AL, et al: Mechanical stretching stimulates smooth muscle cell growth, nuclear protein import, and nuclear pore expression through mitogen-activated protein kinase activation. J Biol Chem 2007; 282: 23081-23088.

15) Shah MR, Wedgwood S, Czech L, et al: Cyclic stretch induces inducible nitric oxide synthase and soluble guanylate cyclase in pulmonary artery smooth muscle cells. Int J Mol Sci 2013; 14: 4334-4348.

16) Starke RM, Chalouhi N, Ding D, et al: Vascular smooth muscle cells in cerebral aneurysm pathogenesis. Transl Stroke Res 2014; 5: 338-346.

17) Dufourcq P, Louis H, Dandré F, et al: Phenotypic modification of arterial smooth muscle cells in response to medial dissection. Coron Artery Dis 1997; 8: 163-170.

18) Ogawa J, Fujiwara H, Kawamura A, et al: Acute cellular damage in medial smooth muscle cells following experimental coronary angioplasty in dog. Damage of cytoskeleton and apoptosis. Heart Vessels 1997; 12: 157-166.

19) Badel P, Avril S, Sutton MA, et al: Numerical simulation of arterial dissection during balloon angioplasty of atherosclerotic coronary arteries. J Biomech 2014; 47: 878-889.

20) Zuo D, Avril S, Yang H, et al: Three-dimensional numerical simulation of soft-tissue wound healing using constrainedmixture anisotropic hyperelasticity and gradient-enhanced damage mechanics. J R Soc Interface 2020; 17: 20190708.

21) Savardekar AR, Patra DP, Nanda A, et al: Retrograde trans-posterior communicating artery rescue balloon angioplasty of incompletely expanded pipline embolization device: complication management. Br J Neurosurg 2020; 18: 1-4.

22) Griessenauer CJ, Jain A, Enriquez-Marulanda A, et al: Pharmacy-mediated antiplatelet management protocol compared to one-time platelet function testing prior to pipeline embolization of cerebral aneurysms: a propensity score-matched cohort study. Neurosurgery 2019; 84: 673-679. 